\title{
Cryobiology in human ARTs: then and now
}

\author{
David F. Albertini ${ }^{1}$ \\ Published online: 20 July 2018 \\ (C) Springer Science+Business Media, LLC, part of Springer Nature 2018
}

Headlining JARG this month is first a systematic review of how the biophysical properties of the ovary control key signaling events linked to normal physiology and disease conditions like PCOS (Biomechanics and mechanical signaling in the ovary: a systematic review. https://doi.org/10.1007/s10815-018-1180) followed by a critical and thought-provoking analysis of how we as practitioners of human ARTs stand relative to the evolving world of cryobiology around us.

Before taking on the challenging topic of cryobiology, our readership will hopefully gain new insights regarding matters of sperm-insourcing and what may underlie the not infrequent observation of cleavage failure in so many IVF and ICSI cycles. What is trending, and hence recommended, when the effectiveness of surgically retrieved sperm (i.e., of the nonejaculated variety) is evaluated through registry data bases is discussed by Jindal and Sparks (Synergy at work: two heads are better than one. https://doi.org/10.1007/s10815-0181250). And finally, how early cleavage defects may be traced back to gene products deposited in the developing oocyte or azoospermic patients (A novel mutation in the TUBB8 gene is associated with complete cleavage failure in fertilized eggs. https://doi.org/10.1007/s10815-018-1188; Azoospermia and embryo morphokinetics: testicular spermderived embryos exhibit delays in early cell cycle events and increased arrest prior to compaction. https://doi.org/10.1007/ s10815-018-1183).

Onto the matter of cryobiological applications in human ARTs. As this issue goes to production, the Society for Cryobiology is holding its annual meeting in Madrid, and a quick visit to their website will greet you with a definition for cryobiology as "the science of life at icy temperatures" (https://www.societyforcryobiology.org/). Surveying the

David F. Albertini

eicjarg@gmail.com

1 Center for Human Reproduction, New York, NY, USA meeting program brings to light just how far away human ARTs are from current and ongoing efforts to achieve efficient, reversible, and safe cryopreservation strategies. Admittedly, the charge for such a Society of specialists is two-pronged in both teasing apart the nuances of how many organisms manage to survive in low temperature environments and extend technologies for cell, tissue, and organ preservation within the realm of contemporary medicine. Our profession has taken important cues from the discipline in the past, but are we keeping pace with the latest advances or settling into a complacent attitude?

Given the timely and consistent introduction, adoption, and widespread utilization of cryopreservation in human ARTs over nearly three decades now, one would hope sentinels of change in technology would have graced our menu options for patients. And they have! In today's society, the notion that oocyte cryopreservation is losing fashion would be nothing short of heretical. Why? The gradual displacement of slowfreeze technology by vitrification welcomed a fastidious if not fanatical segue to "vit," heralded initially at an ASRM meeting quasi-debate, and followed shortly thereafter by the ribbon-cutting announcement that the ASRM would remove the label of "experimental" when it came to the clinical utility of oocyte cryopreservation [1].

The importance of registry building cannot be underestimated as the business of oocyte cryopreservation has clearly penetrated a market outside the realm of traditional infertility [2], and will hopefully be recognized and used by all practitioners of ARTs regardless of their commercial interests. While the entry of the vitrification strategy continues to receive validation for most all cryostorage needs encountered in IVF clinics [3], it is important to bear in mind that our current methodologies are not without limitations that include fundamental disturbances in ion balance, not easily rectified within the context of the wide-ranging array of warming protocols yet to be implemented in a uniform and practical manner [4]. And as has been discussed previously [5], matters of standardization bear on both oocyte and embryo cryopreservation given the use of high concentrations of cryoprotectants used in 
vitrification relative to slow-freeze protocols of yesteryear, which derived from far more basic research.

At this juncture, it is interesting to consider exactly where the bar was set in determining the effectiveness of cryopreservation in human ARTs. Granted the foundational work done on mammalian oocytes and embryos set the stage early on for establishing just how sensitive human oocytes might be to even transient episodes of cooling. And the target for study was an obvious one - the meiotic spindle - that provider of tracks and motors along which maternal chromosomes would successfully complete their segregation and deployment into zygote or polar body. No small wonder then when it was shown that cooling destroyed the spindle [6], paranoia reigned supreme such that bench temperature stability became a quasilegitimate obsession for everyday practice in the ART laboratory, and the spindle secured its rightful position as the dominant sentinel of whether a cryo protocol would pass muster on the road to clinical effectiveness. Not unexpectedly, there was a lot more to it including the basic survival principle - life or death after warming.

As far as spindle integrity went, patient age and time of thawing were shown to play a prominent role not only in recovery of the meiotic spindle but also in the timing of chromosome realignment [7]. And when compared to vitrified oocytes, distinct parameters were identified relative to the behaviors observed in slow-frozen human oocytes [8], while closer examination is reinforcing just how disruptive vitrification is despite survival and recovery of a spindle [9]. What does this all mean?

While solid positive clinical outcomes sustain our uses of cryopreservation in everyday practice, and continue to gain widespread adoption for the various indications calling for fertility preservation, there is room for improvement as long as we are willing to keep close watch on what goes on around us in other medical disciplines.

It is towards this end we bring our readership to the front lines of research and applications for human ARTs from a cryobiological perspective. We welcome any and all feedback from you. And finally, we thank all of our editorial board members, contributors, reviewers, and followers for their involvement that has brought the impact factor for JARG to a record high.

\section{References}

1. Practice Committees of American Society for Reproductive M, Society for Assisted Reproductive T. Mature oocyte cryopreservation: a guideline. Fertil Steril 2013;99(1):37-43.

2. Nagy ZP, Anderson RE, Feinberg EC, Hayward B, Mahony MC. The Human Oocyte Preservation Experience (HOPE) Registry: evaluation of cryopreservation techniques and oocyte source on outcomes. Reprod Biol Endocrinol. 2017;15(1):10.

3. Rienzi L, Gracia C, Maggiulli R, LaBarbera AR, Kaser DJ, Ubaldi FM, et al. Oocyte, embryo and blastocyst cryopreservation in ART: systematic review and meta-analysis comparing slow-freezing versus vitrification to produce evidence for the development of global guidance. Hum Reprod Update. 2017;23(2):139-55.

4. Nikiforaki D, Vanden Meerschaut F, Qian C, De Croo I, Lu Y, Deroo $\mathrm{T}$, et al. Oocyte cryopreservation and in vitro culture affect calcium signalling during human fertilization. Hum Reprod. 2014;29(1):2940.

5. Quaas AM, Hansen KR. Time to "cool off"? Examining indications for "elective deferred frozen embryo transfer". J Assist Reprod Genet. 2016;33(12):1551-2.

6. Pickering SJ, Braude PR, Johnson MH, Cant A, Currie J. Transient cooling to room temperature can cause irreversible disruption of the meiotic spindle in the human oocyte. Fertil Steril. 1990;54(1):102-8.

7. Bromfield JJ, Coticchio G, Hutt K, Sciajno R, Borini A, Albertini DF. Meiotic spindle dynamics in human oocytes following slowcooling cryopreservation. Hum Reprod. 2009;24(9):2114-23.

8. Coticchio G, Bromfield JJ, Sciajno R, Gambardella A, Scaravelli G, Borini A, et al. Vitrification may increase the rate of chromosome misalignment in the metaphase II spindle of human mature oocytes. Reprod BioMed Online. 2009;19(Suppl 3):29-34.

9. Nottola SA, Albani E, Coticchio G, Palmerini MG, Lorenzo C, Scaravelli G, et al. Freeze/thaw stress induces organelle remodeling and membrane recycling in cryopreserved human mature oocytes. J Assist Reprod Genet. 2016;33(12):1559-70. 